\title{
A Modified “Re-bending of Dentsply Matrix Piece Pushing Gingival" Method to Restore the Adjacent Sub-Gingival Teeth Defect Targeting Special Population
}

\author{
Fengze wang ${ }^{1 \#}$, Fangchong $\mathrm{Du}^{1 \#}$, Jiao Wen ${ }^{2 \#}$, Bo Qiao ${ }^{3}$, Rui Zhao ${ }^{3}$, Haifeng Meng ${ }^{4}$, Mingfang Shu ${ }^{5}$, Xun Chen*1 \\ ${ }^{1}$ Department of stomatology, The $316^{\text {th }}$ Hospital of Chinese People's Liberation Army, China
}

${ }^{2}$ State Key Laboratory of Military Stomatology \& National Clinical Research Center for Oral Diseases \& Shaanxi Engineering Research Center for Dental Materials and Advanced Manufacture, Department of Anesthesiology, The Fourth Military Medical University, China

${ }^{3}$ Department of stomatology, Chinese People's Liberation Army General Hospital, China

${ }^{4}$ Department of stomatology, Binzhou people's hospital, China

${ }^{5}$ Binzhou Ling Hang dental hospital, China

"Fengze Wang, Fangchong Du and Jiao Wen are contributed equally to the article

Received: 制: September 06, 2018; Published: 阱 September 17, 2018

*Corresponding author: Xun Chen, Department of stomatology, The316 ${ }^{\text {th }}$ Hospital of Chinese People's Liberation Army, No. A2 Niangniangfu, Xiangshan Road, Haidian District, Beijing, China

\begin{abstract}
Better adjacency is of significant importance to the function of teeth. The disruption of teeth adjacency would cause food impaction, dental caries and periodontal problems. Many cases, adjacent alveolar bone absorption result in food level impaction. Long-time food accumulation in gingival triangle zone can lead to teeth defect below the adjacent gingival. The bottom of the defect is difficult to see clearly, bringing great trouble of application of matrix system. Unreasonable placement of matrix piece will prone to appear resin overhanging, pressing the gingival. Hence, we summarized a modified "re-bending of Dentsply matrix piece pushing gingival" method to restore teeth defect below the adjacent gingival efficiently.
\end{abstract}

\section{Introduction}

Better contact relationship of teeth is crucial to the teeth function. The purpose of resin restoration is to re-form the adjacency of the teeth and to ensure no marginal overhang existence [1,2].

Often, theadjacentalveolarboneabsorption will causehorizontal food impaction, which is the important reason to the teeth caries and periodontal disease below the adjacent gingival $[3,4]$. The big problem is that we are difficult to see clearly the bottom of defect.

\section{Patients and Method}

Rubber dam is the important tool to restore the teeth defect. However, there will be a limited population featured as restricted mouth opening, allergic to rubber dam and intolerance to long-time mouth opening. We couldn't apply rubber dam to these population. Hence, we create a modified "re-bending of Dentsply matrix piece pushing gingival" method to restore the defect more quickly. We rebend the Dentsply matrix piece based on the shape of the defect area. Next, we apply the Dentsply matrix system to push the gingival to the subgingival defect section (Figures 1-3). 


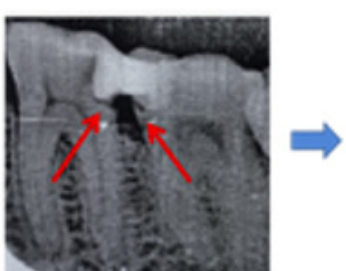

Step 1

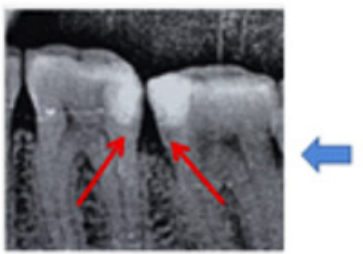

Step 8

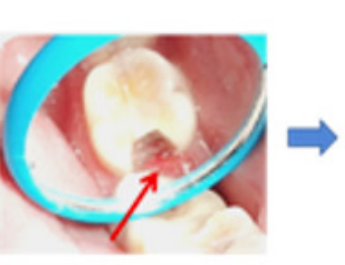

Step 2

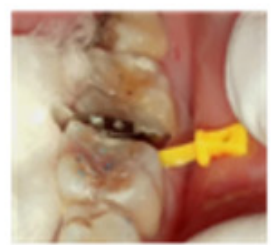

Step 7

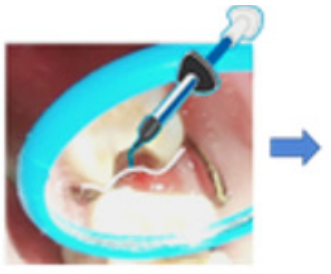

Step 3
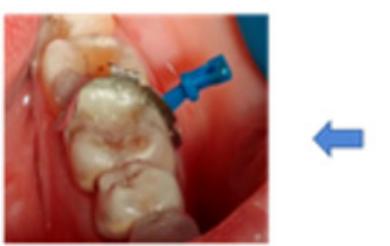

Re-besdiaz matrix piece following the shape of step 5

\section{Step 6}

Figure 1: Re-bending matrix piece to push the gingival method.

- $\quad$ Step 1: Unproper resin restoration showing in the radiograph.

- $\quad$ Step 2: After removing the unproper resin restoration, the tooth defect area is covered by the gingiva.

- Step3: Inflamed gingival contraction using gingival retraction cord. Application of a layer of flowing resin to the gingival retraction cord.

- $\quad$ Step 4, 5: Application of curing light (Coltolux LED) to cure flowable resin. This will indirectly reflect the shape of the decay on the root surface below the gingiva.

- $\quad$ Step 6: Re-bending matrix piece following the shape of step 5.

- $\quad$ Step 7: Placement of re-bended matrix piece and restore the defect area using resin.

- Step 8: The radiograph after resin restoration. The results of the restoration are as expected.
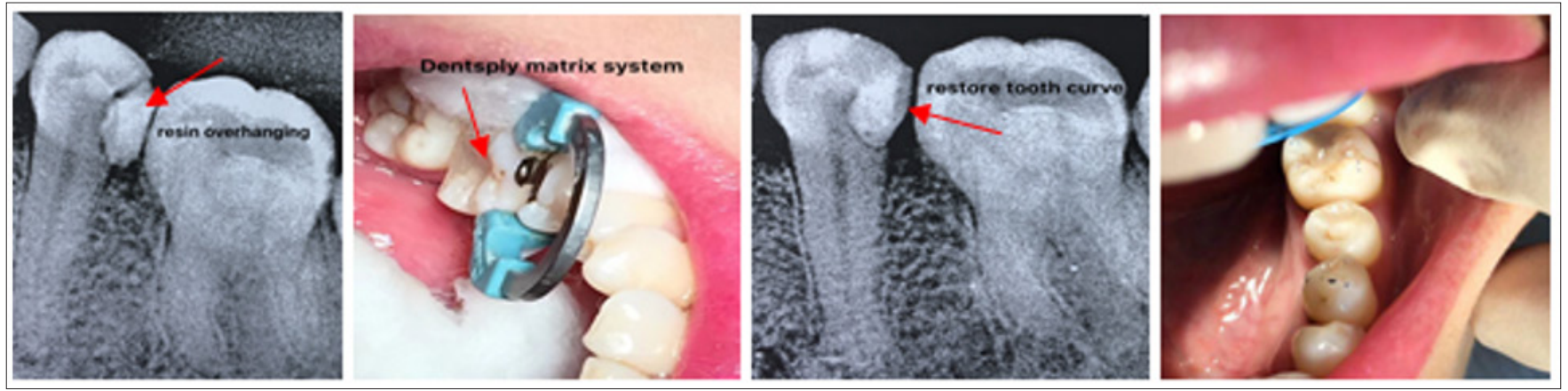

Figure 2: Restoring the distal subgingival tooth defect using Dentsply matrix system. 

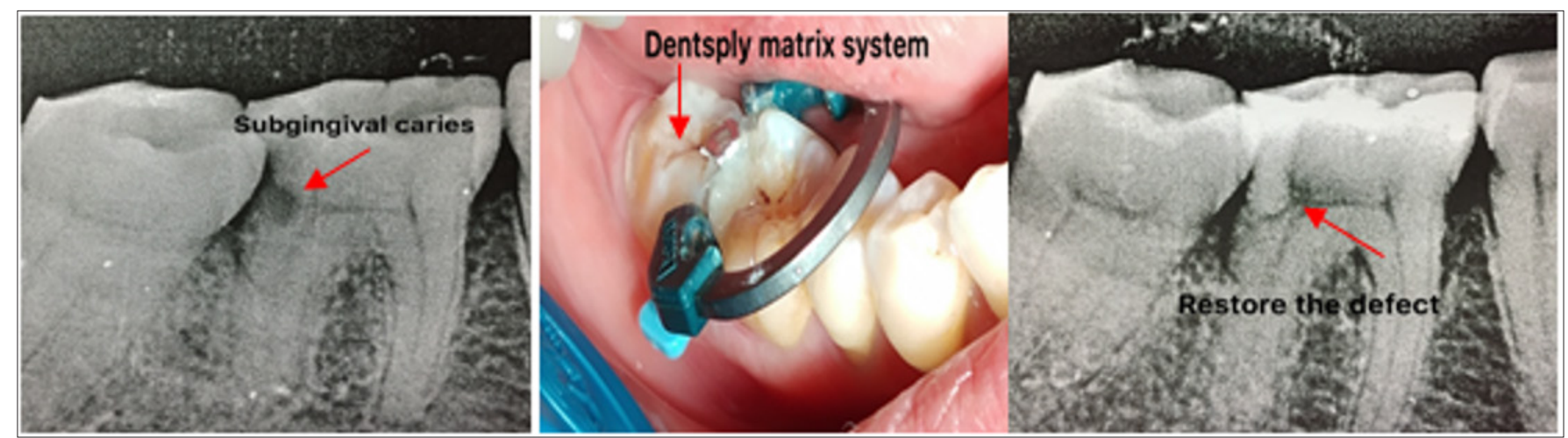

Figure 3: Restoring the distal subgingival tooth defect using Dentsply matrix system.

\section{Conclusion}

Repairing the subgingival teeth defect is a very difficult affair. This reformative method combined with Dentsply matrix system could assist doctors to restore the complicate caries relatively more easily. It could repair the subgingival tooth defect of special population better and faster.

\section{Acknowledgement}

We express our great gratitude to Jianhua Wei for his help.

ISSN: 2574-1241

DOI: 10.26717/BJSTR.2018.09.001747

Xun Chen. Biomed J Sci \& Tech Res

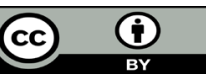

This work is licensed under Creative Commons Attribution 4.0 License

Submission Link: https://biomedres.us/submit-manuscript.php

\section{References}

1. Loomans BA, Opdam NJ, Roeters FJ, Bronkhorst EM, Huysmans MC (2009) Restoration techniques and marginal overhang in Class II composite resin restorations. J Dent 37: 712-717.

2. Abrams H, Kopczyk RA (1983) Gingival sequela from a retained piece of dental floss. J Am Dent Assoc 106: 57-58.

3. Takei HH (1980) The interdental space. Dent Clin North Am 24: 169-176.

4. Jernberg GR, Bakdash MB, Keenan KM (1983) Relationship between proximal tooth open contacts and periodontal disease. J Periodontol 54: 529-533.

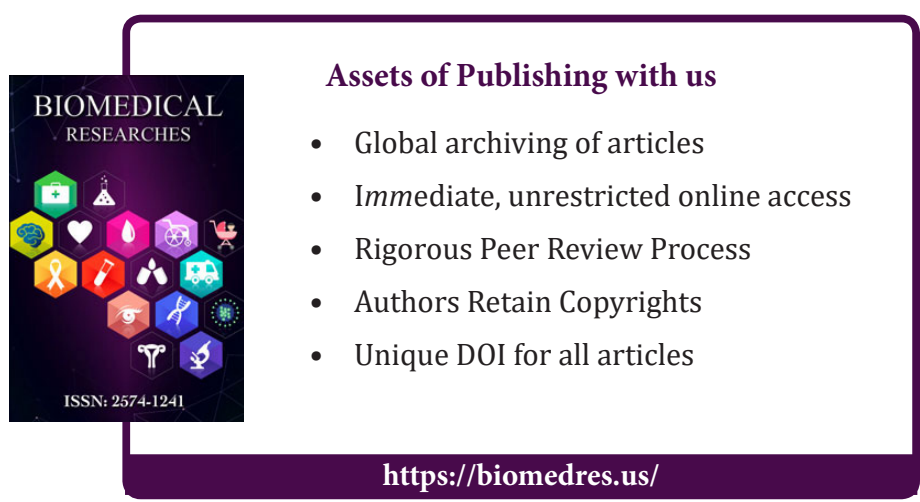

Cite this article: Fengze w, Fangchong D, Jiao W, Bo Q, Rui Z, Haifeng M, Mingfang S, Xun C. A Modified “Re-bending of Dentsply Matrix Piece 